\title{
Targeting Nuclear NOTCH2 by Gliotoxin Recovers a Tumor-Suppressor NOTCH3 Activity in CLL
}

\author{
Rainer Hubmann ${ }^{1,2, *} \mathbb{\infty}$, Susanne Schnabl ${ }^{1}$, Mohammad Araghi ${ }^{1}$, Christian Schmidl ${ }^{3,4} \oplus$, \\ André F. Rendeiro ${ }^{3}$, Martin Hilgarth ${ }^{1}$, Dita Demirtas ${ }^{1}$, Farghaly Ali ${ }^{1}{ }^{\circledR}$, Philipp B. Staber ${ }^{1}$, \\ Peter Valent ${ }^{1,5}$, Christoph Zielinski ${ }^{1,2}$, Ulrich Jäger ${ }^{1,2}$ and Medhat Shehata ${ }^{1,2,5, *(D)}$ \\ 1 Department of Internal Medicine I, Division of Hematology \& Hemostaseology, Medical University of \\ Vienna, 1090 Vienna, Austria; susanne.schnabl@meduniwien.ac.at (S.S.); \\ mohammad.araghi@meduniwien.ac.at (M.A.); martin.hilgarth@meduniwien.ac.at (M.H.); \\ dita.demirtas@meduniwien.ac.at (D.D.); alifarghly.1980@gmail.com (F.A.); \\ philipp.staber@meduniwien.ac.at (P.B.S.); peter.valent@meduniwien.ac.at (P.V.); \\ christoph.zielinski@meduniwien.ac.at (C.Z.); ulrich.jaeger@meduniwien.ac.at (U.J.) \\ 2 Comprehensive Cancer Center Vienna, Drug and Target Screening Platform DTS, Medical University of \\ Vienna, 1090 Vienna, Austria \\ 3 CeMM Research Center for Molecular Medicine of the Austrian Academy of Sciences, 1090 Vienna, Austria; \\ christian.schmidl@ukr.de (C.S.); arendeiro@cemm.oeaw.ac.at (A.F.R.) \\ 4 Regensburg Center for Interventional Immunology (RCI), Franz-Josef-Strauss-Allee 11, \\ 93053 Regensburg, Germany \\ 5 Ludwig Boltzmann Institute for Hematology and Oncology, Medical University of Vienna, \\ 1090 Vienna, Austria \\ * Correspondence: medhat.shehata@meduniwien.ac.at (M.S.); rainer.hubmann@meduniwien.ac.at (R.H.); \\ Tel.: +43-1-40400-44140 (M.S.)
}

Received: 28 April 2020; Accepted: 8 June 2020; Published: 18 June 2020

\begin{abstract}
NOTCH signaling represents a promising therapeutic target in chronic lymphocytic leukemia (CLL). We compared the anti-neoplastic effects of the nuclear NOTCH2 inhibitor gliotoxin and the pan-NOTCH $\gamma$-secretase inhibitor RO4929097 in primary CLL cells with special emphasis on the individual roles of the different NOTCH receptors. Gliotoxin rapidly induced apoptosis in all CLL cases tested, whereas RO4929097 exerted a variable and delayed effect on CLL cell viability. Gliotoxin-induced apoptosis was associated with inhibition of the NOTCH2/FCER2 (CD23) axis together with concomitant upregulation of the NOTCH3/NR4A1 axis. In contrast, RO4929097 downregulated the NOTCH3/NR4A1 axis and counteracted the spontaneous and gliotoxin-induced apoptosis. On the cell surface, NOTCH3 and CD23 expression were mutually exclusive, suggesting that downregulation of $\mathrm{NOTCH} 2$ signaling is a prerequisite for NOTCH3 expression in CLL cells. ATAC-seq confirmed that gliotoxin targeted the canonical NOTCH signaling, as indicated by the loss of chromatin accessibility at the potential $\mathrm{NOTCH} / \mathrm{CSL}$ site containing the gene regulatory elements. This was accompanied by a gain in accessibility at the NR4A1, NFKB, and ATF3 motifs close to the genes involved in B-cell activation, differentiation, and apoptosis. In summary, these data show that gliotoxin recovers a non-canonical tumor-suppressing NOTCH3 activity, indicating that nuclear NOTCH2 inhibitors might be beneficial compared to pan-NOTCH inhibitors in the treatment of CLL.
\end{abstract}

Keywords: chronic lymphocytic leukemia (CLL); NOTCH2; NOTCH3; FCER2 (CD23); NR4A1; gliotoxin; RO4929097; $\gamma$-secretase inhibitors; ATAC-seq; binary cell fate decision; positive/negative selection; CD5+ B-cell homeostasis 


\section{Introduction}

Chronic lymphocytic leukemia (CLL) is considered an antigen-driven B-cell neoplasm, characterized by clonal expansion of mature CD5+ B-lymphocytes [1-6]. Despite its clinical heterogeneity, a consistent feature of CLL cells is the overexpression of NOTCH1 and NOTCH2 [7-10]. NOTCH1 is affected by gain-of-function mutations in a subset of CLL cases (10 to $15 \%$ ), where it is considered to be an independent prognostic marker associated with disease progression [11-17]. The high nuclear NOTCH2 activity is not only a hallmark of all CLL cases-where it is associated with the expression of the B-cell activation/differentiation marker CD23-but is also functionally linked with CLL cell viability $[7,8,18]$.

The conserved NOTCH gene family (NOTCH1-4) encodes transmembrane receptors that regulate a wide variety of differentiation processes by modulating binary cell fate decisions in response to external signals [19-22]. Canonical NOTCH signaling is induced by ligand binding, the intracellular domain of $\mathrm{NOTCH}\left(\mathrm{N}^{\mathrm{IC}}\right)$ is released by a series of proteolytic events involving $\gamma$-secretase followed by translocation to the nucleus, where it acts as context and cell type specific transcription factor on CSL (for CBF1, Suppressor of Hairless, and LAG-1)-responsive genes like FCER2 (CD23) in CLL cells $[7,18,20-22]$. However, non-canonical NOTCH signaling also exists and involves the activation of $\mathrm{NF \kappa B}$ [23]. In the murine system, Notch2 is implicated in the development of marginal zone (MZ) B2 B-cells and of Cd5+ (B-1a) B-lymphocytes [24], and is indispensable for CLL initiation in Cd5+ (B-1a) B-cells [25].

Deregulation of NOTCH signaling is observed in an increasing number of human neoplasms, where the individual NOTCH receptors act either as oncogenes or as tumor suppressors, depending on the cellular context and microenvironment $[20,26,27]$. Therefore, targeting oncogenic NOTCH, for example with $\gamma$-secretase inhibitors (GSI), represents a promising therapeutic strategy in the treatment of NOTCH-associated tumors/leukemias [27-31]. In a first attempt to address this issue, we found that the majority of CLL cases express GSI-resistant NOTCH2/CSL transcription factor complexes and did not respond to the selective GSI DAPT [18]. In contrast, targeting nuclear NOTCH2 with the Aspergillum-derived NOTCH2/CSL transactivation inhibitor, gliotoxin efficiently induced apoptosis in CLL cells by a mechanism involving the induction of the NOTCH3 and the NR4A1 gene on the mRNA level [32]. However, the global effect of gliotoxin on the complex and interconnected signal transduction pathways and the role of NOTCH3 in CLL cells remains to be determined.

In the current study, we extended our prior work and compared the anti-neoplastic effects of gliotoxin and the GSI RO4929097 [29,31,33] in a reasonable cohort of well-characterized CLL cases. Here we show that the inhibition of NOTCH2 signaling by gliotoxin is associated with the recovery of a potentially non-canonical tumor suppressing NOTCH3 activity in CLL cells. Furthermore, assays for transposase-accessible chromatin with high-throughput sequencing (ATAC-seq) revealed that gliotoxin treatment is associated with prominent changes in the epigenetic landscape in CLL cells.

\section{Materials and Methods}

\subsection{Patients' Characteristics and Sample Collection}

Heparinized peripheral blood was obtained from 33 CLL patients after signed informed consent (MUW-IRB approval numbers 495/2003, 11/2005, and 36/2007). Peripheral blood mononuclear cells (PBMC) were isolated using Ficoll-Hypaque (GE Healthcare, Uppsala, Sweden) centrifugation. CLL cases were screened for characteristic CLL chromosomal aberrations by FISH analysis. The IGHV and NOTCH1 mutational status was determined by Sanger sequencing (LGC Genomics, Berlin, DE). The GSI sensitivity of nuclear NOTCH2 was determined by quantification of DNA-bound NOTCH2/CSL transcription factor complexes in CLL cells $\pm 0.5 \mu \mathrm{M}$ RO4929097 after one day of incubation using electrophoretic mobility shift assays (EMSA), essentially as described [18]. The NOTCH2 (C651.6DbHN) antibody used for the supershift/interference assays was obtained from the Developmental Studies 
Hybridoma Bank (University of Iowa, Department of Biological Science, Iowa City, IA, United States). The patients' characteristics are summarized in Table 1.

Table 1. Clinical and prognostic parameters of the chronic lymphocytic leukemia (CLL) samples enrolled in this study.

\begin{tabular}{|c|c|c|c|c|c|c|c|c|}
\hline Pat. ID & Age & Gender & $\begin{array}{l}\text { Rai/Binet } \\
\text { Stage }\end{array}$ & $\begin{array}{l}\text { IGHV } \\
\text { Status }\end{array}$ & $\begin{array}{l}\text { Cytogenetic } \\
\text { Alterations }\end{array}$ & $\begin{array}{l}\text { NOTCH1 } \\
\text { Mutations }\end{array}$ & $\begin{array}{l}\text { NOTCH2 } \\
\text { GSI-R/S* }\end{array}$ & Treatment \\
\hline CLL1 & 76 & male & II/B & $\mathrm{U}, V H 2-5$ & normal & $N 1 \Delta C T$ & GSI-S & no \\
\hline CLL2 & 69 & male & II/B & $\mathrm{U}, \mathrm{VH1-69}$ & normal & $N 1 \Delta C T$ & GSI-R & no \\
\hline CLL3 & 70 & male & $\mathrm{IV} / \mathrm{C}$ & M, VH4-34 & Tri12 & wt & ND & no \\
\hline CLL4 & 64 & male & II/B & M, VH3-23 & $13 q-, 17 p-$ & wt & ND & no \\
\hline CLL5 & 51 & female & $\mathrm{IV} / \mathrm{C}$ & $\mathrm{U}, V H 1-69$ & normal & wt & ND & no \\
\hline CLL6 & 56 & male & $\mathrm{IV} / \mathrm{C}$ & M, VH3-21 & $13 q^{-}, 11 q^{-}$ & wt & GSI-S & no \\
\hline CLL7 & 68 & male & $\mathrm{II} / \mathrm{B}$ & M, VH3-48 & $13 q_{-}, 11 \mathrm{q}-$ & wt & GSI-R & no \\
\hline CLL8 & 84 & male & $\mathrm{I} / \mathrm{A}$ & NA & normal & wt & GSI-R & no \\
\hline CLL9 & 81 & female & $\mathrm{I} / \mathrm{A}$ & M, VH3-15 & $13 q-$ & wt & GSI-R & no \\
\hline CLL10 & 73 & female & $\mathrm{IV} / \mathrm{C}$ & M, VH3-23 & normal & wt & GSI-S & no \\
\hline CLL11 & 66 & female & $\mathrm{I} / \mathrm{A}$ & M, $V H 3-48$ & $13 q-$ & wt & GSI-R & no \\
\hline CLL12 & 70 & male & $\mathrm{I} / \mathrm{A}$ & M, VH1-8 & $13 q-$ & wt & GSI-R & no \\
\hline CLL13 & 66 & female & $\mathrm{II} / \mathrm{B}$ & M, VH3-23 & $13 q-$ & wt & GSI-R & no \\
\hline CLL14 & 75 & female & $\mathrm{IV} / \mathrm{C}$ & NA & $13 q-$ & wt & GSI-S & no \\
\hline CLL15 & 65 & male & $\mathrm{I} / \mathrm{A}$ & $\mathrm{U}, \mathrm{VH1}-69$ & $14 q 32-$ & wt & GSI-R & no \\
\hline CLL16 & 52 & male & $\mathrm{IV} / \mathrm{C}$ & $\mathrm{U}, \mathrm{VH1-69}$ & normal & wt & GSI-S & no \\
\hline CLL17 & 55 & male & II/B & $\mathrm{U}, V H 3-11$ & $13 q^{-}, 11 q-$ & wt & GSI-R & Ibrutinib \\
\hline CLL18 & 40 & female & $\mathrm{I} / \mathrm{A}$ & $\mathrm{U}, \mathrm{VH} 3-20$ & normal & wt & GSI-S & no \\
\hline CLL19 & 68 & female & III/B & $\mathrm{U}, \mathrm{VH1}-2$ & $13 q-$ & $N 1 \Delta C T$ & GSI-S & no \\
\hline CLL20 & 60 & male & $\mathrm{IV} / \mathrm{C}$ & $\mathrm{U}, \mathrm{VH} 1-46$ & $13 q^{-}, 11 q-$ & $N 1 \Delta C T$ & GSI-S & no \\
\hline CLL21 & 52 & male & $\mathrm{II} / \mathrm{B}$ & NA & $13 q-$ & ND & GSI-R & no \\
\hline CLL22 & 70 & female & II/B & M, VH3-13 & $13 q-$ & ND & GSI-S & no \\
\hline CLL23 & 54 & male & $\mathrm{I} / \mathrm{A}$ & $\mathrm{U}, \mathrm{VH} 3-53$ & normal & ND & ND & no \\
\hline CLL24 & 77 & female & $\mathrm{IV} / \mathrm{C}$ & NA & $17 p-$ & ND & ND & no \\
\hline CLL25 & 54 & male & $\mathrm{I} / \mathrm{A}$ & $\mathrm{U}, \mathrm{VH} 4-39$ & $11 \mathrm{q}-$ & ND & ND & Duvelisib \\
\hline CLL26 & 69 & male & $\mathrm{II} / \mathrm{B}$ & $\mathrm{U}, \mathrm{VH} 3-21$ & $13 q-$ & ND & ND & Ibrutinib \\
\hline CLL27 & 70 & male & $\mathrm{II} / \mathrm{B}$ & M, VH3-13 & $13 q-$ & ND & ND & no \\
\hline CLL28 & 61 & female & $\mathrm{I} / \mathrm{A}$ & M, VH3-7 & normal & ND & ND & no \\
\hline CLL29 & 77 & female & II/B & M, VH3-74 & normal & ND & ND & no \\
\hline CLL30 & 87 & female & $\mathrm{IV} / \mathrm{C}$ & M, VH3-11 & $13 q-$ & ND & ND & Idealisib \\
\hline CLL31 & 68 & female & $\mathrm{II} / \mathrm{B}$ & M, VH3-48 & $13 q-$ & ND & ND & no \\
\hline CLL32 & 83 & female & II/B & M, VH4-59 & $13 q-$ & ND & ND & Ibrutinib \\
\hline CLL33 & 60 & male & $\mathrm{II} / \mathrm{B}$ & $\mathrm{U}, \mathrm{VH1}-69$ & $13 q-/ 11 q-$ & ND & ND & Idealisib \\
\hline
\end{tabular}

33 CLL patients were matched in terms of age, gender, Rai/Binet stages, IgVH mutational status and cytogenetic aberrations. CLL1-20 were used for initial drug screening and CLL21-33 were additionally used for follow-up and validation experiments. Abbreviations: U, IGHV unmutated; M, IGHV mutated; ND, not determined; NA, not amplifiable; N1 $\triangle C T$ indicates the recurrent NOTCH1 microdeletion; wt indicates wild type. NOTCH2 GSI-R/S* indicates the expression of the GSI-resistant/sensitive DNA-bound NOTCH2/CSL complexes.

\subsection{Chemical Reagents, Compounds, and Culture}

RO4929097 was purchased from Selleckchem (Houston, TX, USA). DAPT (N-[N-(3,5Difluorophenacetyl)-L-alanyl]-S-phenylglycine t-butyl ester); gliotoxin, the NFKB activation inhibitor 6-amino-4-(4-phenoxyphenylethylamino)quinazoline, and PMA (Phorbol-12-myristat-13-acetat) were obtained from Merck Millipore (Darmstadt, DE). All compounds were reconstituted in dimethyl sulfoxide (DMSO). PBMCs from CLL patients were cultured in RPMI 1640 supplemented with 10\% heat-inactivated fetal calf serum (FCS), $2 \mathrm{mM}$ Glutamine, $100 \mathrm{U} / \mathrm{mL}$ penicillin, and $100 \mathrm{mg} / \mathrm{mL}$ streptomycin (all reagents were obtained from Gibco, Life Technologies Inc., Paisley, UK).

\subsection{Flow Cytometry and Detection of Cell Viability}

Antibodies against CD5, CD19, and CD23 were purchased from eBioscience (San Diego, CA, USA). The anti-human NOTCH3 antibody (Clone MHN3-21) was purchased from BioLegend 
(San Diego, CA, USA). Flow cytometry was performed on a FACSCalibur ${ }^{\mathrm{TM}}$ using CellQuest Pro software (Becton Dickinson, San Jose, CA, USA). AnnexinV and propidium iodide staining was performed to estimate the percentages of cells undergoing apoptosis. Apoptosis was calculated as the sum of early apoptotic (Ax+/PI-) and late apoptotic/necrotic (Ax+/PI+) cells using a kit from eBioscience (San Diego, CA, USA). Cell viability/metabolic activity was evaluated by a nonisotopic MTT (3-(4,5-dimethylthiazolyl-2)-2,5-diphenyltetrazolium bromide) assay (Ez4U) (Biomedica, AT).

\subsection{Reverse Transcription Polymerase Chain Reaction (RT-PCR) Analysis}

Total RNA was extracted using the TRI Reagent ${ }^{\circledR}$ isolation system (Sigma-Aldrich, St Louis, MO, USA). M-MLV reverse transcriptase and GoTaq PCR kits (Promega, WI, USA) were used for semi quantitative RT-PCR. The MYC primer sequences used in this study read as follows: forward 5'-GAAAACAATGAAAAGGCCCC-3' and reverse 5'-TTCCTTACGCACAAGAGTTC-3'. Primer sets for NOTCH1, NOTCH2, NOTCH3, FCER2, NR4A1, and ACTB were published elsewhere [32]. PCR bands were stained with GelRedTM (Biotium, Fremont, CA, USA) and visualized using the ChemiDocTM gel imaging system from Bio-Rad (Hercules, CA, USA).

\subsection{Gene Silencing by RNA-Interference}

The siRNA duplexes (siRNAs) for NOTCH3 (ON-TARGETplusTM) and the controls (RISC-free Co-siRNA, and siGLO red transfection indicator) were obtained from Dharmacon (Lafayette, CO, USA). Transfection of siRNAs into the CLL cells was performed by using the lipid reagent siLentFect ${ }^{\mathrm{TM}}$ from Bio-Rad Laboratories (Hercules, CA, USA). The transfection efficiency was determined by FACS and varied from 70 to $90 \%$.

\subsection{ATAC-Seq}

Accessible-chromatin mapping on the CLL cells was performed using the ATAC-seq method with minor modifications together with the ATAC-seq processing pipeline, as described previously $[34,35]$. Principle component analysis (PCA) was performed on the quantile-normalized log-transformed values of chromatin accessibility across all the accessible sites discovered in all samples, and DESeq2 was used to detect the differential regions between treatment timepoints across patients [36]. Regions with an FDR-adjusted p-value smaller than 0.05 were selected and clustered using the Euclidean distance and complete linkage, from which two clusters representing the earliest branching point were extracted. HOMER [37] was used for de novo motif finding on the region clusters and LOLA [38] for enrichment in previously existing location-based datasets. Genes assigned to the two clusters of regions were enriched using the Enrichr tool [39].

\section{Results}

\subsection{Dose and Time-Dependent Effects of Gliotoxin and GSI on CLL Cell Viability}

Eighteen CLL cases (Table 1) were subjected to MTT assays and the dose-dependent effect of gliotoxin, RO4929097, and DAPT (0.01 to $10 \mu \mathrm{M})$ on cell viability was determined after 3 and 7 days of incubation.

After 3 days, gliotoxin efficiently decreased CLL cell viability (IC50 between $0.1 \mu \mathrm{M}$ and $1 \mu \mathrm{M}$ ), whereas RO2949097 and DAPT were only partly effective in a subset of patient samples, including those cases characterized by the NOTCH1 $\triangle C T$ mutation (Figure 1A-C). The mean inhibition of CLL cell viability $( \pm \mathrm{SD})$ in the NOTCH1 wild type versus NOTCH1 $\triangle C T$ mutated CLL cases at an inhibitor concentration of $0.5 \mu \mathrm{M}$ after 3 days was as follows: $84 \%( \pm 23 \%)$ versus $87 \%( \pm 16 \%)$ for gliotoxin, $14 \%$ $( \pm 13 \%)$ versus $36 \%( \pm 14 \%)$ for RO4929097, and $10 \%( \pm 14 \%)$ versus $33 \%( \pm 16 \%)$ for DAPT, respectively. 

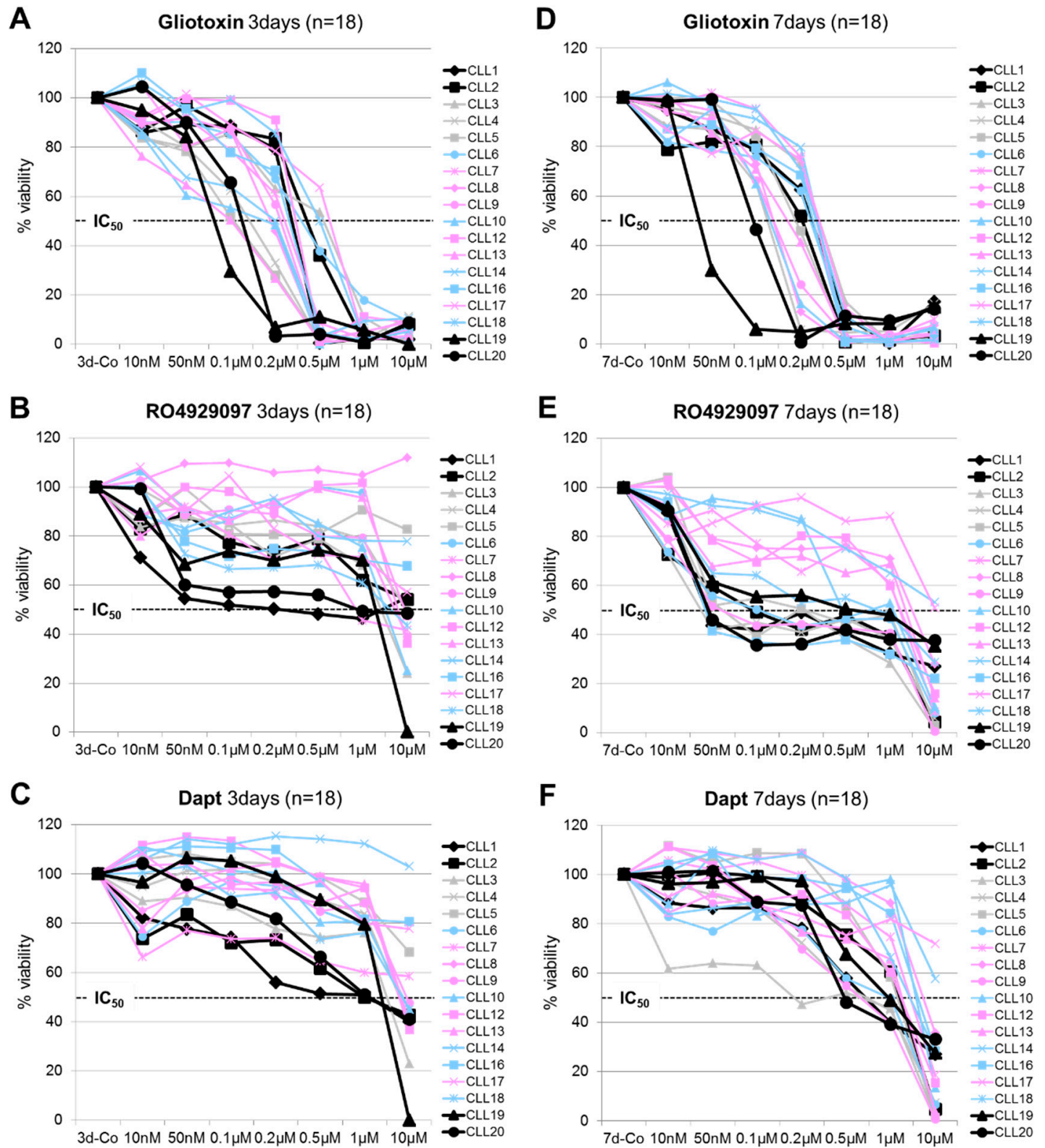

Figure 1. The dose- and time-dependent effect of gliotoxin, RO4929097, and DAPT on CLL cell viability in vitro. Eighteen CLL cases, including 4 cases with the recurrent NOTCH1 $\triangle C T$ mutation (black lines), 6 cases expressing GSI-R nuclear NOTCH2 (pink lines), and 5 cases expressing GSI-S nuclear NOTCH2 (blue lines), were subjected to MTT assays and the relative inhibition of cell viability in response to the indicated drug concentrations was determined after $3(\mathbf{A}-\mathbf{C})$ and 7 days $(\mathbf{D}-\mathbf{F})$, respectively. The percent inhibition relative to the controls was calculated from the mean OD (optical density) values from CLL samples cultured in triplicates. The $\mathrm{IC}_{50}$ of the individual compounds is indicated.

After 7 days, the response to RO4929097 was more prominent and 11 out of the 18 treated CLL cases $(61 \%)$ reached $\mathrm{IC}_{50}$ levels at a drug concentration of $0.5 \mu \mathrm{M}$ (Figure $1 \mathrm{E}$ ) and, thus, were phenotypically considered as GSI sensitive. The NOTCH1 $\triangle$ CT mutated CLL cases and/or CLL cases expressing the GSI-sensitive (GSI-S) nuclear NOTCH2 clustered in this GSI-sensitive group. In contrast, CLL cases expressing GSI-resistant (GSI-R) nuclear NOTCH2 and with the wild type (wt) NOTCH1 status clustered in the GSI-resistant group. Maximal responses were already achieved at $0.1 \mu \mathrm{M}$ RO4929097 and increasing amounts did not significantly enhance its effect on the CLL cells. The drop in CLL cell viability at higher drug concentrations $(10 \mu \mathrm{M})$ after this plateau phase might be 
attributed to off-target effects (Figure 1B,E) [40]. The mean inhibition of CLL cell viability $( \pm$ SD) in the NOTCH1wT versus NOTCH1 $\triangle$ CT mutated CLL cases at an inhibitor concentration of $0.5 \mu \mathrm{M}$ after 7 days was as follows: $95 \%( \pm 6 \%)$ versus $92 \%( \pm 5 \%)$ for gliotoxin, $40 \%( \pm 20 \%)$ versus $54 \%( \pm 7 \%)$ for RO4929097, and $22 \%( \pm 17 \%)$ versus $38 \%( \pm 12 \%)$ for DAPT, respectively.

\subsection{GSI Inhibited Spontaneous Apoptosis in Early Clinical Stage-Derived CLL Samples Expressing GSI Resistant Nuclear NOTCH2}

The observed delayed effect of GSI on CLL cell viability in the MTT assays suggests that GSI primarily affect the metabolic activity rather than directly inducing apoptosis. Therefore, we measured the percentage of apoptotic CLL cells $(n=16)$ after exposure to equal doses $(0.5 \mu \mathrm{M})$ of gliotoxin, RO4929097, and DAPT by AnnexinV/PI staining.

After 3 days, gliotoxin significantly induced apoptosis in all CLL samples $(p<0.001)$, whereas the effects of GSI were moderate (Figure 2A). After 7 days, GSI had a variable effect on CLL cell apoptosis (Figure 2B). RO4929097 increased apoptosis in CLL cases expressing GSI-S nuclear NOTCH2 $(p=0.003 ; n=7)$ and, surprisingly, decreased apoptosis in CLL cases expressing GSI-R nuclear NOTCH2 ( $p=0.001 ; n=9)$ (Figure 2C), irrespective of the NOTCH1 mutational status (Figure 2D). Interestingly, the anti-apoptotic effect of GSI was restricted to CLL samples derived from Rai/Binet I/A and II/B patients (CLL2, CLL7, CLL8, CLL9, CLL11, CLL12, CLL13, CLL15, and CLL17), whereas a pro-apoptotic effect of GSI was mainly observed in CLL samples derived from Rai/Binet IV/C patients (5 out of 7; CLL6, CLL10, CLL14, CLL16, and CLL20).

\section{A}

A

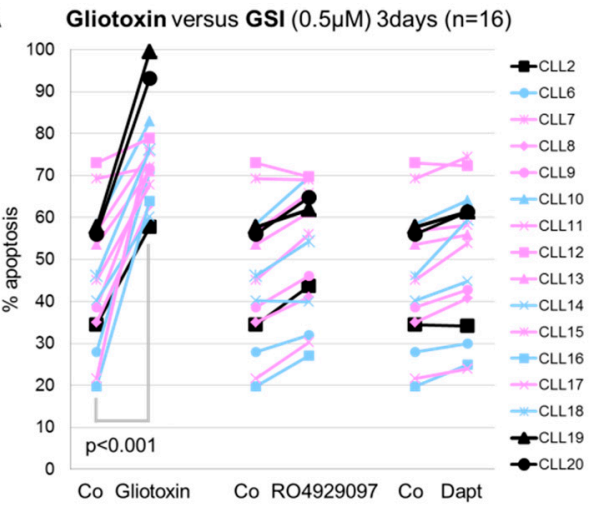

B

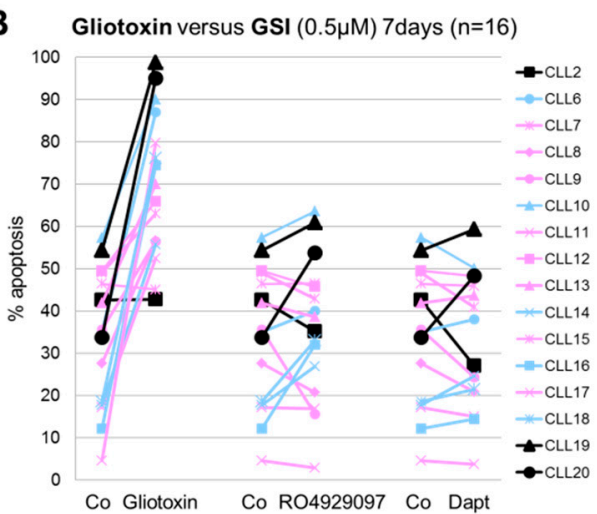

C

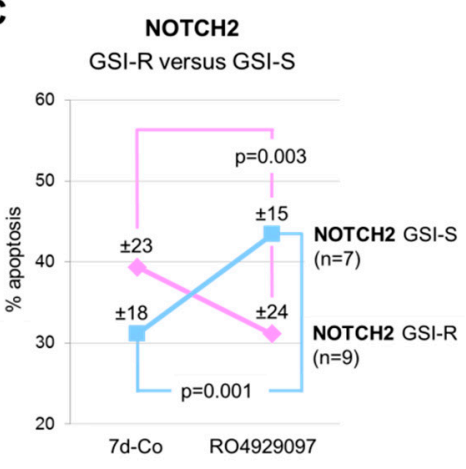

D

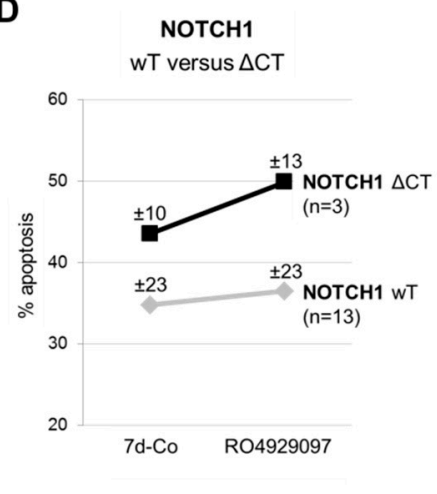

Figure 2. Effect of gliotoxin, RO4929097, and DAPT on apoptosis in CLL cells. Sixteen CLL cases, including 3 cases with the recurrent NOTCH1 $\triangle C T$ mutation (black lines), 8 cases expressing GSI-R nuclear NOTCH2 (pink lines), and 5 cases expressing GSI-S nuclear NOTCH2 (blue lines), were subjected to FACS analysis and the induction/inhibition of apoptosis in response to the indicated drug concentrations relative to controls was determined after 3 (A) and 7 days (B) in suspension cultures. The mean effects $( \pm \mathrm{SD}$ ) of $0.5 \mu \mathrm{M}$ RO4929097 on the percentage of apoptotic CLL cells after 7 days in relation to the GSI sensitivity of NOTCH2 (C) and the NOTCH1 mutational status (D) are indicated. 
3.3. The Inhibition of Spontaneous Apoptosis by RO4929097 is Associated with Inhibition of Recovered NOTCH3 mRNA Expression in CLL Cells

We next confirmed in a time kinetic RT-PCR experiment in two additional representative CLL samples (CLL21, 22) our previous observation that gliotoxin inhibited NOTCH2, to a lesser extent NOTCH1, and induced NOTCH3 mRNA expression within $4 \mathrm{~h}$ of incubation (Figure 3A) [32]. Interestingly, RO4929097 counteracted gliotoxin-induced NOTCH3 transcription after one day (Figure 3A). This suggests that RO4929097 interrupted a positive feedback loop of NOTCH3 mRNA expression. NOTCH receptors regulate context and cell type specific their own expression and each other in positive and negative feedback loops [19]. Moreover, RO4929097 decreased (58 versus 64\%) or increased (86 versus 79\%) the effect of gliotoxin on the percentage of apoptotic cells, depending on the GSI sensitivity of nuclear NOTCH2 (Figure 3A). Therefore, we asked whether NOTCH3 might also account for the GSI-mediated inhibition of spontaneous apoptosis in early clinical stage-derived CLL long-term suspension cultures.

NOTCH3 mRNA was not detectable in frozen samples from freshly isolated CLL cells of our initial drug screening cohort (Figure 3C). After 7 days, however, the anti-apoptotic effect of RO4929097 in two representative Rai/Binet I/A patient samples expressing GSI-R nuclear NOTCH2 (CLL8 and CLL9, Figure 3B) was clearly associated with inhibition of spontaneously recovered NOTCH3 mRNA expression, together with unchanged or even enhanced NOTCH2 mRNA and NOTCH2/CSL DNA-complex expression (Figure 3C, left panel).

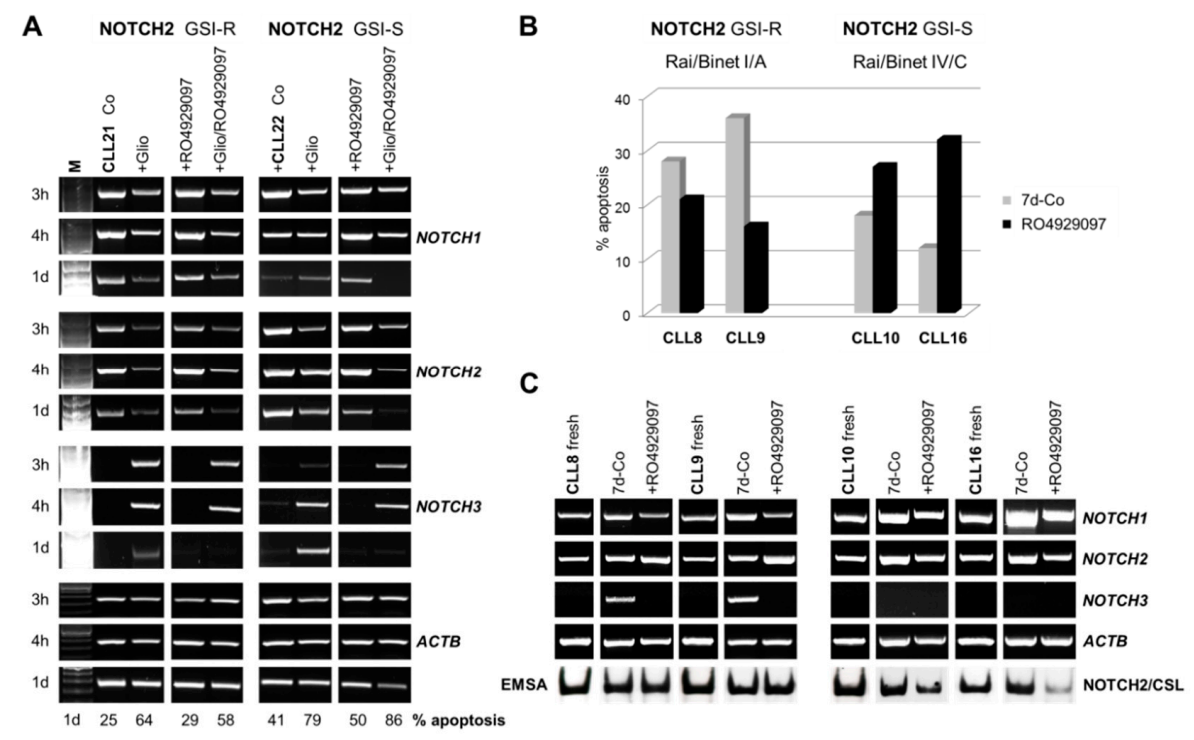

Figure 3. RO4929097 inhibited gliotoxin-induced and basal NOTCH3 mRNA expression in CLL cells. (A) Time kinetic RT-PCR analysis showing NOTCH1, NOTCH2, and NOTCH3 mRNA expression in response to $0.2 \mu \mathrm{M}$ gliotoxin and/or $0.5 \mu \mathrm{M}$ RO4929097 treatment in relation to the GSI sensitivity of nuclear NOTCH2. For co-treatment, CLL cells were first incubated with RO4929097 immediately before adding gliotoxin. The effect of the compounds on the percentage of apoptotic CLL cells after 1 day in culture is indicated. (B) FACS analysis indicating the inhibition/induction of apoptosis by RO4929097 $(0.5 \mu \mathrm{M})$ in fresh CLL samples derived from two representative NOTCH2 GSI-R Rai/Binet I/A and two representative NOTCH2 GSI-S Rai/Binet IV/C CLL patient samples after 7 days in culture. (C) Corresponding RT-PCR showing the effect of RO4929097 $(0.5 \mu \mathrm{M})$ on NOTCH1, NOTCH2, and recovered NOTCH3 mRNA expression on Day 7. The GSI resistance/sensitivity of nuclear NOTCH2/CSL DNA-complexes is indicated by EMSA. ACTB was included as the internal control.

In contrast, the induction of apoptosis by RO4929097 in two representative Rai/Binet IV/C patient samples expressing GSI-S nuclear NOTCH2 (CLL10 and CLL16, Figure 3B) was associated with a decrease in NOTCH2 mRNA and NOTCH2/CSL DNA-complex expression without any detectable 
$\mathrm{NOTCH} 3$ gene activity after 7 days in culture (Figure 3C, right panel). In accordance with published data $[9,16]$, the NOTCH1 mRNA was GSI sensitive in all cases and was more expressed in the Rai/Binet IV/C-derived CLL cells (Figure 3C).

Together, this combined approach suggests that recovery of NOTCH3 mRNA expression is involved in the inhibition of spontaneous apoptosis by GSI in CLL long-term suspension cultures and may be associated with GSI resistance of NOTCH2 and early stage derived CLL samples.

3.4. Induction of Surface NOTCH3 Expression by Gliotoxin is Associated with Downregulation of CD23 and Increased Apoptosis of CLL Cells

We next analyzed NOTCH3 and FCER2 (CD23) expression in CLL cells $(\mathrm{n}=4)$ in relation to spontaneous as well as gliotoxin induced apoptosis on the mRNA and protein level by RT-PCR and FACS (Figure 4; see Supplemental Figure S1 for a detailed FACS analysis of CLL24 cells). NOTCH3 was almost undetectable on the mRNA (Figure 4A) and on the cell surface protein level (Figure 4B) in freshly isolated CLL cells. After 4 days in culture, we found an increase of surface NOTCH3 expression together with a decrease in surface CD23 on CLL23 and CLL24 cells (Figure 4B). On the mRNA level, NOTCH3 expression was below the detection limit in the 4 days control. The loss of $\mathrm{CD} 23$ expression seemed to be a prerequisite for NOTCH3 expression since NOTCH3 was primarily detected on CD23-negative CLL cells.

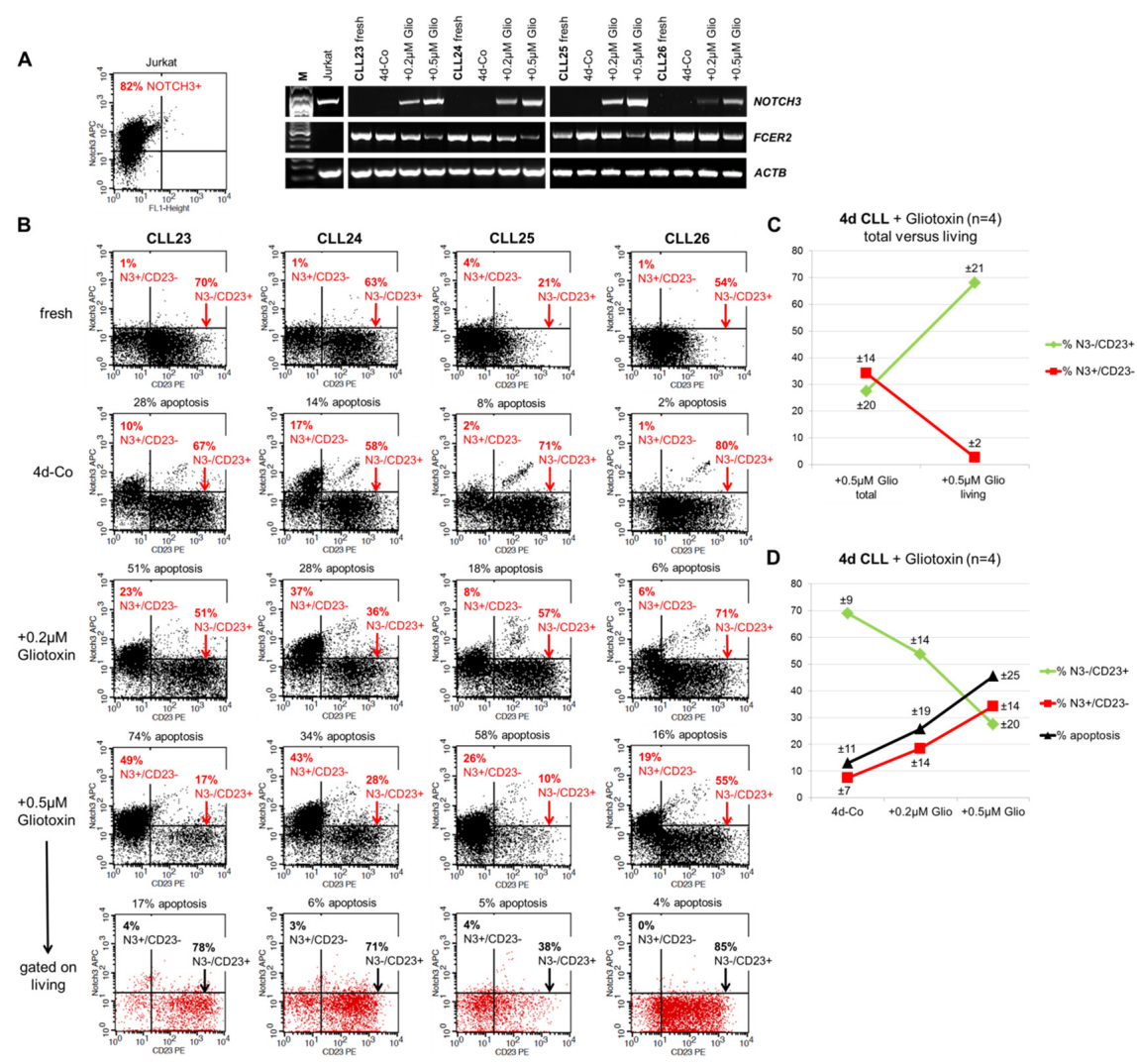

Figure 4. NOTCH3 and CD23 surface expression are mutually exclusive on CLL cells. (A) RT-PCR and (B) FACS showing NOTCH3 and FCER2 (CD23) expression in freshly isolated CLL cells and after 4 days in culture in relation to surface CD23 expression and spontaneous as well as gliotoxin-induced apoptosis. The T-ALL cell line Jurkat served as positive control for NOTCH3 mRNA and NOTCH3 surface expression. (C) Gating on the remaining living cells after gliotoxin treatment according to their forward/side scatter properties revealed that living CLL cells were enriched for NOTCH3-/CD23+ cells. (D) Summary of the FACS data, demonstrating a direct correlation of the percentage of NOTCH3+/CD23and apoptotic CLL cells and an indirect correlation of these two parameters with the percentage of NOTCH3-/CD23+ CLL cells. Data presented as means $( \pm \mathrm{SD})$. 
In contrast, we detected a low expression of CD23 on freshly isolated cells from Duvelisib (CLL25) or Ibrutinib (CLL26) treated CLL patients (Figure 4B). However, FCER2 (CD23) expression spontaneously recovered on the mRNA and protein level in these 2 samples after 4 days in culture which might be attributed to the loss of the inhibitory effect of these drugs on CD23 over time (Figure 4A,B).

Gliotoxin induced the NOTCH3 gene (Figure 4A), enhanced NOTCH3 surface expression, and upregulated apoptosis in a dose-dependent manner in all cases (Figure 4B). The remaining living CLL cells were enriched for CD23-positive and NOTCH3-negative cells (Figure 4B,C and Figure S1), confirming that CD23 expression is associated with CLL cell viability whereas NOTCH3 expression is associated with CLL cell apoptosis.

In summary, we found a direct correlation between the percentage of surface NOTCH3-positive and apoptotic CLL cells and an indirect correlation of these two parameters with the percentage of CD23-positive and living CLL lymphocytes (Figure 4D).

\subsection{Targeting NOTCH3 Signaling Decreased NR4A1 mRNA Expression and Counteracted Gliotoxin Induced Apoptosis in CLL Cells}

We hypothesized that NOTCH2 and NOTCH3 have opposite roles in the binary cell fate decision between positive and negative selection of the activated CLL cells. Therefore, we investigated the effects of targeting NOTCH3 by RO4929097, or more specifically, by siRNA in PMA-stimulated CLL cells [32]. In this model, CLL cells form tight clusters and express the CLL proliferation center marker MYC (Figure 5B), resembling the situation found in lymphoid tissues [41,42]. To avoid background effects on NOTCH2 signaling, we selected five CLL cases expressing GSI-R NOTCH2 (CLL7, 8, 9, $13,21)$.

A time kinetic confirmed that CD23 was expressed on almost all representative CLL9 cells after one day of PMA stimulation (Figure 5A) [18]. Interestingly, prolonged stimulation with PMA for 3 days led to the downregulation of $\mathrm{CD} 23$, upregulation of $\mathrm{NOTCH}$, and an increase in the percentage of apoptotic CLL9 cells. This effect was clearly enhanced by gliotoxin treatment (Figure 5A).

As expected, gliotoxin induced the NOTCH3/NR4A1 axis, downregulated the NOTCH2/FCER2 (CD23) axis, and inhibited the NOTCH2/CSL transcription factor complex within $4 \mathrm{~h}$ of incubation (Figure 5B, left panel) [32]. In accordance with the FACS data, the NOTCH3/NR4A1 axis was also upregulated in PMA-stimulated CLL9 cells after 3 days in culture without gliotoxin treatment (Figure 5B, right panel). Neither gliotoxin nor PMA induced DNA-bound NOTCH3/CSL complexes in EMSA. RO4929097 inhibited the NOTCH3/NR4A1 axis, upregulated the NOTCH2/FCER2 (CD23) axis, and enhanced the NOTCH2/CSL transcription factor complex (Figure 5B, right panel), which stands in sharp contrast to the effect of gliotoxin. The NOTCH1 target gene MYC was downregulated by RO4929097 (Figure 5B, right panel) [9,43-45].

The opposite effects of gliotoxin and RO4929097 on the NOTCH2/FCER2 (CD23) axis and the NOTCH3/NR4A1 axis were reflected by the opposite effects of these compounds on CLL cell viability. As shown in Figure 5C, gliotoxin remarkably induced apoptosis $(n=5$, mean $\% \pm$ SD: $85 \pm 5 \%$ versus $23 \pm 6 \%$ ), while RO4929097 significantly decreased spontaneous ( $10 \pm 2 \%$ versus $23 \pm 6 \% ; p=0.009$ ) as well as gliotoxin-induced apoptosis ( $53 \pm 9 \%$ versus $85 \pm 5 \% ; p=0.001)$ in CLL cells.

NOTCH3 gene silencing by siRNA decreased the apoptotic effect of the gliotoxin, leading to a 3.5-fold increase in (Ax-/PI-) living CLL9 cells with increased surface CD23 expression after 3 days in culture (Figure 5D). Corresponding RT-PCR analysis confirmed that NOTCH3 gene silencing downregulated the NOTCH3/NR4A1 axis and upregulated the NOTCH2/FCER2 (CD23) axis (Figure 5E), resembling the effect of GSI treatment (Figure 5B, right panel). Interestingly, gliotoxin-mediated upregulation of the NR4A1 gene was completely blocked by an NFKB activation inhibitor (Figure $5 \mathrm{~F}$ ), suggesting that NOTCH3 regulates NR4A1 transcription via non-canonical NOTCH3/NFkB signaling [23,46,47]. This would explain the lack of DNA-bound NOTCH3/CSL complexes in EMSA. All other control experiments show similar trends. 
Collectively, these data strongly suggest that inhibition of the anti-apoptotic canonical NOTCH2/CSL signaling (NOTCH2/FCER2 axis) by gliotoxin recovers a GSI sensitive pro-apoptotic non-canonical NOTCH3 function which may involve $\mathrm{NFKB}$ dependent NR4A1 expression (NOTCH3/NR4A1 axis) in CLL cells. A hypothetical model summarizing the proposed counteracting roles of NOTCH2 and NOTCH3 in CLL cells is given in Figure 5G.

A

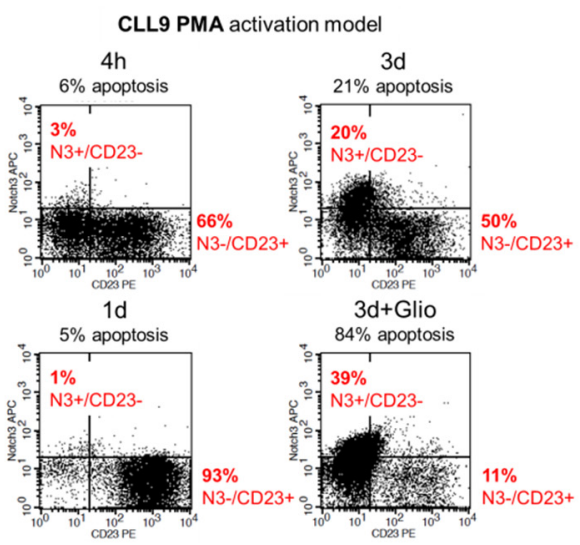

D

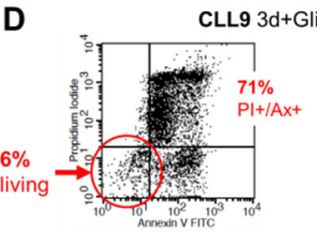

CLL9 3d+Glio/NOTCH3-siRNA

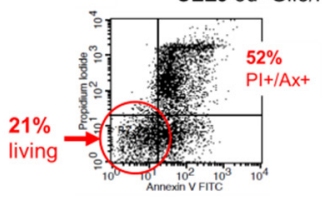

E
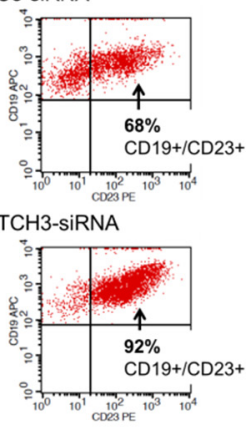

B

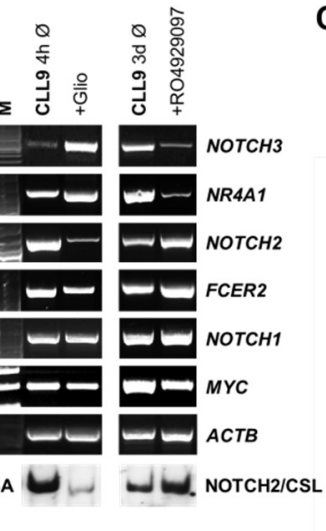

$\mathbf{F}$

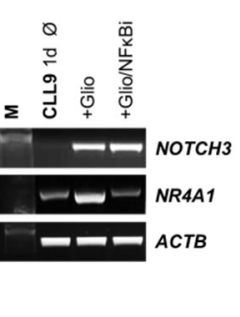

C
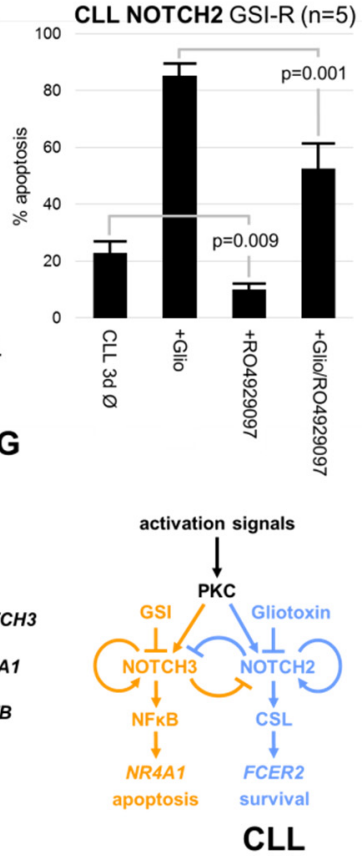

Figure 5. NOTCH3 inhibition counteracts apoptosis in PMA-activated CLL cells. (A) FACS analysis indicating the time-dependent effect of PMA $(1 \mathrm{ng} / \mathrm{mL})$ on surface NOTCH3 and CD23 expression in CLL9 cells. (B) Corresponding RT-PCR showing the opposite effects of gliotoxin $(0.2 \mu \mathrm{M})$ and RO4929097 $(0.5 \mu \mathrm{M})$ on the NOTCH2/FCER2 (CD23) axis and the NOTCH3/NR4A1 axis in PMA-activated CLL9 cells. The mRNA expression of the CLL proliferation center marker MYC is indicated [41,42]. (C) FACS analysis demonstrating the inhibition of spontaneous/gliotoxin induced apoptosis by RO4929097 in NOTCH2 GSI-R CLL cells. (D) NOTCH3-siRNA counteracted gliotoxin induced apoptosis in PMA-activated CLL9 cells and enhanced surface CD23 expression on the remaining living cells. (E) Corresponding RT-PCR showing the opposite effects of NOTCH3 gene silencing on the NOTCH3/NR4A1 axis and on the NOTCH2/FCER2 axis. (F) RT-PCR showing the inhibition of gliotoxin induced NR4A1 mRNA expression by $0.1 \mu \mathrm{M} N F \kappa B$ activation inhibitor (NFkBi). (G) Hypothetical model summarizing the proposed counteracting roles of NOTCH2 and NOTCH3 in CLL cells. Non-canonical NOTCH3 signaling which involves NFKB dependent NR4A1 expression is shown in yellow color. Canonical NOTCH2 signaling which involves CSL dependent FCER2 (CD23) expression is marked in blue. The NOTCH2 dominance in CLL is indicated. Positive and negative feedback loops of NOTCH receptor expression and function are indicated with circular arrows and bars.

\subsection{Gliotoxin Modulates Chromatin Accessibility at Gene Regulatory Elements Containing Potential} NOTCH/CSL and NR4A1 Binding Sites

We have recently shown that genome-wide mapping of gene-regulatory elements using the transposase-accessible chromatin (ATAC-seq) assay is a useful tool to investigate gene regulation in CLL cells [35]. Therefore, we analyzed gliotoxin-induced chromatin changes in CLL cells after 3 days of incubation ( $n=7$, Figure $6 \mathrm{~A})$, where we identified 62,760 unique chromatin accessible regions 
(Figure S2A). These sites represent mainly enhancers and promoters (Figure S2B, a representative locus spanning the CXCR4 gene region is shown in Figure 6B). Unsupervised principal component analysis (PCA) confirmed that IGHV mutation status is the major source of heterogeneity in chromatin accessibility in CLL cells, as described previously (Figure 6C, left panel) [35]. However, Principle Components 1 and 4 clearly revealed dose-dependent changes in chromatin accessibility in response to gliotoxin treatment (Figure 6C, right panel).

Clustering of significantly changing regions (Figure 7A) segregated the sites into those that lose accessibility (Region Cluster 1, marked in blue) and those that gain accessibility (Region Cluster 2, marked in orange) in response to gliotoxin treatment (representative genomic loci of each cluster are shown in Figure 7B). By overlapping the differential ATAC-seq sites with publicly available transcription factor binding experiments [38], we observed that Region Cluster 1 largely overlaps with the functional NOTCH/CSL binding sites in T-cell acute leukemia cells (Figure S3A). On the other hand, Region Cluster 2 largely overlaps with the functional NFKB binding sites in lymphoblastoid cell lines (Figure S3B).

To get unbiased insights into the potential regulators of differentially accessible regions we carried out de novo motif analysis to discover the enriched DNA binding elements. Differential accessible gene-regulatory elements in Region Cluster 1 were found to be enriched for the promoter-associated motif GFY (general factor Y) and the recognition site for ZNF143, both of which contain the NOTCH/CSL consensus binding site TGGGAA [48]. In Region Cluster 2, we found an enrichment of consensus sites for the transcription factors ATF3, PU.1, NFKB, FLI1, NR4A1 (nur77), and RUNX (Figure 7C).
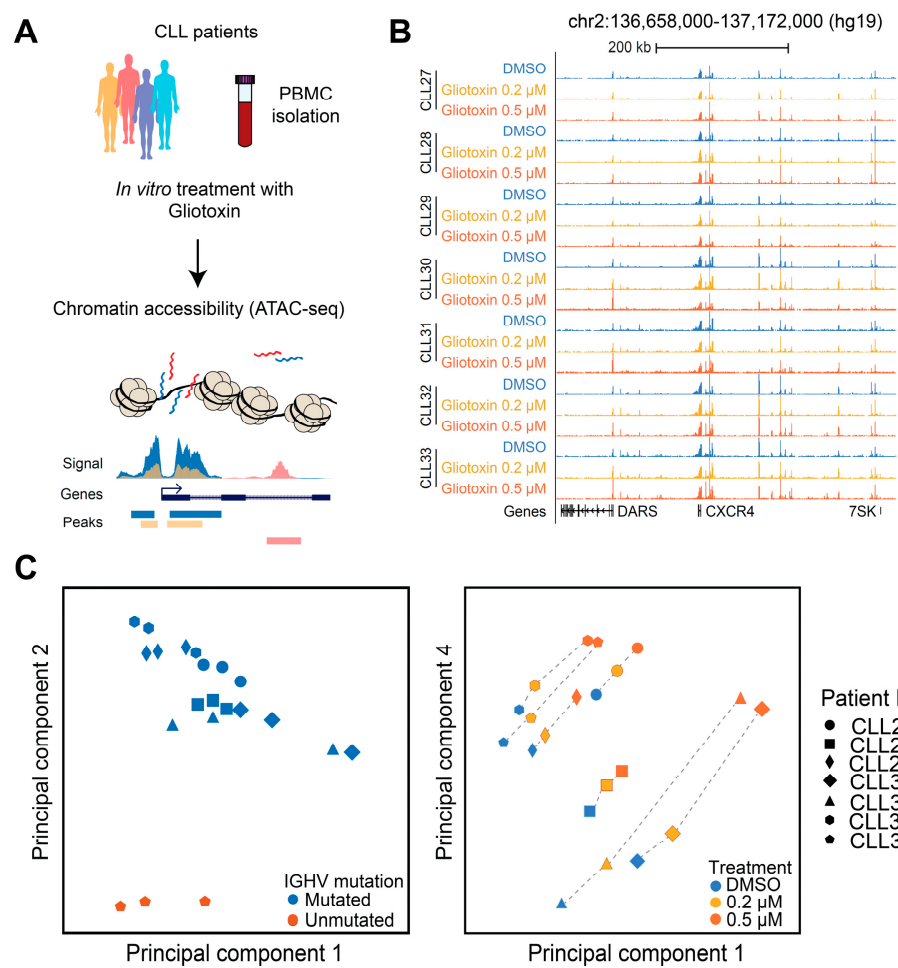

C

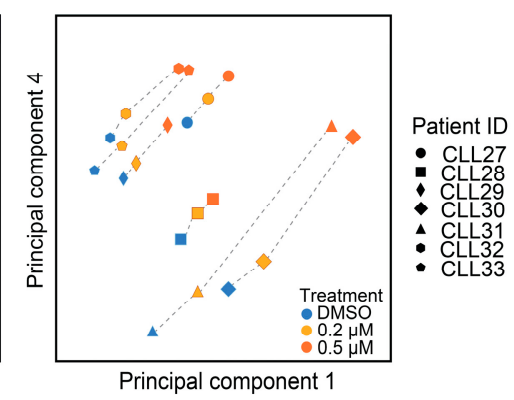

Figure 6. Chromatin accessibility changes in primary CLL cells upon in vitro treatment with gliotoxin. (A) ATAC-seq workflow to study the chromatin accessibility changes of CLL cells in response to gliotoxin treatment. (B) Representative genome browser visualization of the ATAC-seq signals in patient-derived CLL samples $(n=7)$ treated with DMSO and two different concentrations of gliotoxin. A genomic region spanning $\sim 50 \mathrm{~kb}$ around the CXCR4 locus is shown. (C) Unsupervised principal component analysis based on the chromatin accessibility for all 21 samples at all accessible sites in all samples. Samples are color coded according to their IGHV mutation status (left panel), or according to the in vitro treatment condition (right panel). 
A

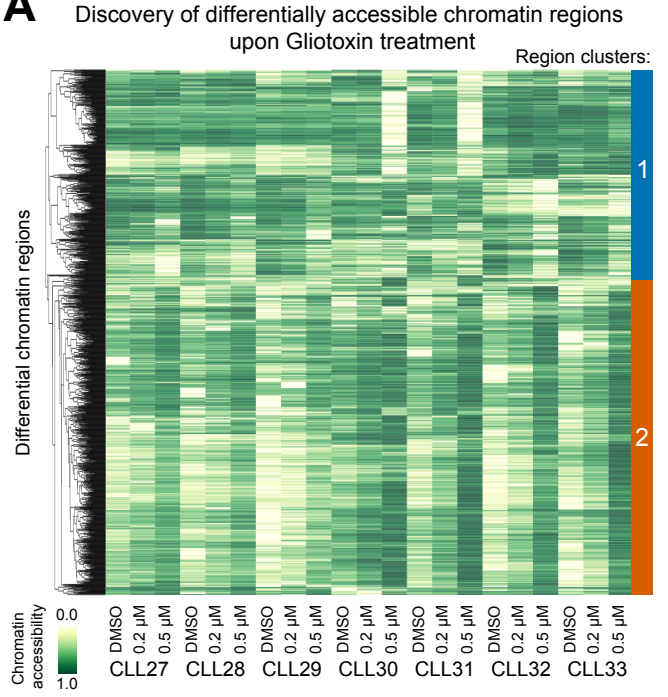

C

De novo motif enrichment in differentially accessible chromatin regions

Region cluster 1 (441 ATAC-seq regions) De novo motif P-value Factor/family (similarity) CIGGGAAATGTAGT $1 \times 10^{-24}$ GFY/? (0.933) TGCATGCTGGAAA 1 × 10-19 ZNF143|STAF/Zf (0.745)
B

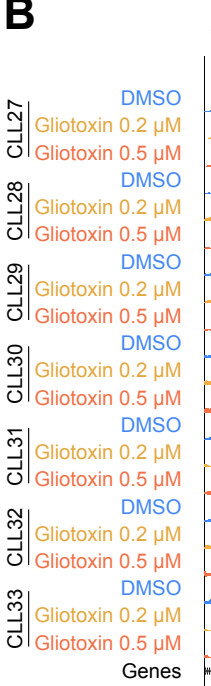

D
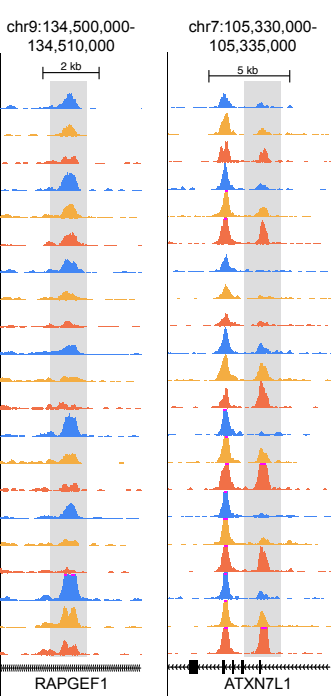

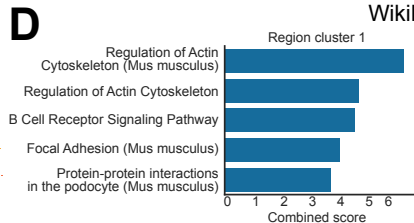

WikiPathways

2 (621 ATAC-seq regions) De novo motif P-value Factor/family (similarity)

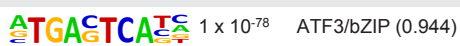

TITCACTTCCTCTI $1 \times 10^{-46}$ PU.1/ETS (0.880)

GGGGATTTCC $1 \times 10^{-39}$ NFkB-p65/RHD (0.948)

TTTCGTGT $1 \times 10^{-24}$ EWS:FLI1/ETS (0.847)

C픈.

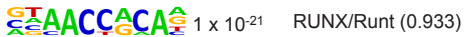
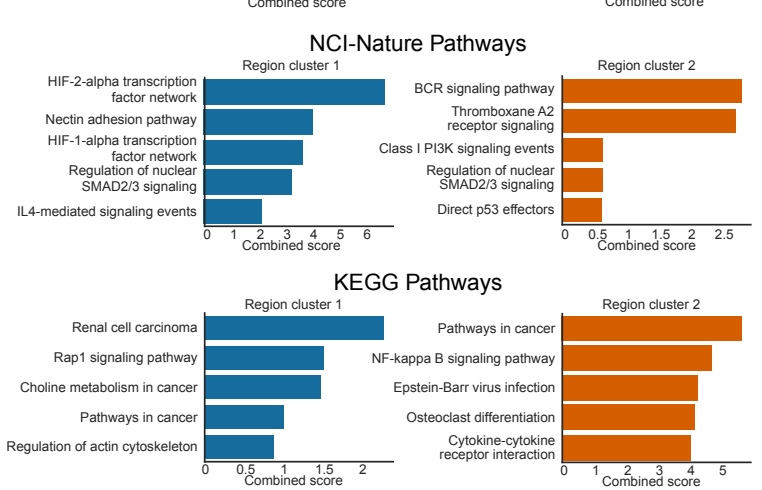

Figure 7. Chromatin gliotoxin treatment-related changes in chromatin accessibility in CLL cells. (A) Clustered heatmap based on all the differentially accessible regions between treatment conditions. (B) Representative browser visualization of genomic regions that lost (left panel for RAPGEF1) or gained (right panel for ATXN7L1) chromatin accessibility upon gliotoxin treatment. (C) De novo motif enrichment analysis of differentially accessible regions from Region Clusters 1 and 2. (D) Most highly enriched pathways for genes associated with Region Clusters 1 and 2.

By linking the differentially accessible regions to their nearest gene, we found that Region Cluster 1 maps toward the genes involved in the regulation of the actin cytoskeleton (ITGB1, ACTN4, MSN, SSH1, and others), HIF-1/2-alpha signaling (VEGFA, HMOX1, TRFC, PLCG2, and others) and RAP1 signaling (RAPGEF1, RAP1A, VAV2, and others) (Figure 7D, see Table S1). Region Cluster 2 was enriched for genes involved in B-cell activation/differentiation (LYN, IRF4, BCL6, ETV6, ARID3A, POU2F2, THEMIS2, IL21R, and others), NFKB signaling (TRAF1-3, RELB, CARD11, and others), TGFß signaling (TGFB1, SMAD3, PML, and others), and apoptosis (FASL, TP73, BBC3, BID, MIR34A, TNFRSF8, GZMB, and others) (Figure 7D, see Table S2).

\section{Discussion}

In the last decade, much effort has been spent into the development of GSIs as tools for therapy for $\mathrm{NOTCH}$-associated human neoplasias [29-31]. However, four NOTCH family members are present in 
mammalian cells, where the individual receptors may have opposite functions concerning their role as oncogenes or tumor suppressors in a context- and microenvironment-dependent manner [26,30,31]. Moreover, transformed cells may express truncated NOTCH forms that do not depend on $\gamma$-secretase for processing and function [49,50]. A search for an alternative to GSI revealed that the Aspergillum-derived secondary metabolite gliotoxin is a potent inhibitor of DNA-bound NOTCH2/CSL transcription factor complexes, and efficiently induced apoptosis in CLL lymphocytes and in NOTCH2-associated solid tumor cell lines-independent of their sensitivity to GSIs [32,51]

In this study, we show that gliotoxin as a nuclear NOTCH2 inhibitor may have an additional therapeutic advantage over GSI as pan-NOTCH inhibitors in CLL. We were able to demonstrate that the GSI RO4929097 targets an unexpected non-canonical tumor-suppressing NOTCH3 activity, which is involved in spontaneous as well as gliotoxin-induced apoptosis in CLL cells.

On the CLL cell surface, upregulation of NOTCH3 was associated with downregulation of CD23, suggesting that downregulation of the NOTCH2/FCER2 (CD23) axis, either spontaneously due to the lack of appropriate activation stimuli in vitro [18], or by gliotoxin treatment [32], is a prerequisite for NOTCH3 expression in CLL cells. The strong association between surface NOTCH3 expression and apoptosis suggests that NOTCH3 signaling is involved in the execution phase of CLL cell apoptosis by prolonging the expression of the newly identified NOTCH3 target gene NR4A1, a multi-functional tumor-suppressor gene implicated in the regulation of B-cell tolerance to self-antigens [52-54].

ATAC-seq confirmed that gliotoxin targets canonical NOTCH signaling as indicated by reduced accessibility at potential NOTCH/CSL consensus sites (TGGGAA) [48]. This includes the promoter-associated motif GFY, and the consensus site for ZNF143, a transcription factor known to modulate NOTCH target gene expression in competition with CSL [55]. In contrast, gliotoxin increased the chromatin accessibility at the potential ATF3, PU.1, NFkB, FLI1, RUNX, and NR4A1 binding sites in the vicinity of genes involved in B-cell activation, differentiation, and apoptosis. This might reflect, at least in part, the loss of a NOTCH2-mediated differentiation arrest and the induction of non-canonical NOTCH3/NFkB signaling [23]. It has been shown that NOTCH3 activates NFKB, a positive regulator of the NR4A1 gene [46], through an IKK $\alpha$-dependent alternative pathway [47]. This would not only explain the gain in chromatin accessibility at NFKB and NR4A1 consensus sites and the lack of DNA-bound NOTCH3/CSL complexes in response to gliotoxin treatment, but also the NOTCH3-dependent NR4A1 gene activity in CLL cells. In line with this assumption, we found that inhibition of NFKB counteracted gliotoxin-mediated upregulation of NR4A1 mRNA in CLL lymphocytes. However, this important issue needs further mechanistic exploration.

NOTCH2 and NOTCH3 signaling antagonize each other in different cell systems [56-59], suggesting that these NOTCH receptors also have opposite functions in the antigen-dependent regulation of $\mathrm{CD} 5+(\mathrm{B}-1 \mathrm{a})$ B-cell homeostasis. Under physiological conditions, NOTCH2 signaling might be induced by ligand-expressing surrounding cells in order to protect the proliferative/regenerative reservoir of CD5+ B-cells from NR4A1-mediated activation-induced cell death (AICD) $[32,52,60]$. This scenario might take place in the marginal zone (MZ) of the spleen [61], where DLL1-expressing bystander cells have been identified [62]. In contrast, apoptotic NOTCH3 signaling might counteract the uncontrolled expansion of CD5+ B-cells in the periphery. In line with this hypothesis, we found that NOTCH3 inhibition by RO4929097, or more specifically, by siRNA, downregulated the NOTCH3/NR4A1 axis, enhanced the NOTCH2/FCER2 (CD23) axis, and counteracted apoptosis in CLL cells. The NOTCH3 gene is frequently epigenetically silenced in B-cell acute lymphocytic leukemia (B-ALL) cells, pointing to a broader tumor-suppressor role of NOTCH3 in B-cells [63]. Moreover, the CLL downregulated/deleted MicroRNA-16 [64] has been shown to exert its pro-apoptotic function by NOTCH2 inhibition in pre-eclampsia, where an inverse correlation between NOTCH2 and NOTCH3 expression also has been found [59].

In terms of CLL biology, constitutive active NOTCH2 might dominantly suppress apoptotic NOTCH3 signaling, thereby enabling the (self-) antigen-driven progredient expansion of the malignant clone. The affinity and avidity of the corresponding (self-) antigens might be the basis for the NOTCH2 
dominance seen in CLL cells. A short time exposure to B-cell activation mimetic PMA favors the NOTCH2/FCER2 (CD23) axis, whereas long-term stimulation with PMA shifts the NOTCH2/FCER2 (CD23) axis to the NOTCH3/NR4A1 axis in CLL cells. One likely mediator of this bi-phasic PMA effect might be the activation and subsequent downregulation of the B-cell receptor-associated protein kinase C-delta (PKC- $\delta$ ) [65-67], a positive regulator of nuclear NOTCH2 activity $[10,18,27,68]$. Therefore, compounds that interfere with B-cell activation might affect the expression of both NOTCH receptors in CLL cells. This would explain why CLL cells pre-treated with Duvelisib (a dual PI3K- $\delta / \gamma$ inhibitor) [69] or Ibrutinib (a Bruton's tyrosine kinase inhibitor) [2,44] express lower amounts of CD23 and NOTCH3 and are less sensitive to apoptosis.

The additional effect of NOTCH1 signaling in this scenario is less clear. NOTCH1 is not detectable in nuclear NOTCH/CSL transcription factor complexes in CLL cells $[7,8,18,32]$. However, NOTCH1 is frequently mutated and/or overexpressed in advanced stage CLL cells, where it has a CLL-driving role by regulating $M Y C$ expression $[8,9,16,17,43-45]$. In this context, NOTCH1 may indirectly account for the relative GSI sensitivity of NOTCH2, keeping in mind that active NOTCH1 is a positive regulator of the NOTCH2 gene in CLL cells (Figure 5G) [12].

\section{Conclusions}

In summary, we show that the nuclear NOTCH2 inhibitor gliotoxin has global effects on the NOTCH signaling network in CLL cells, including the recovery of a newly identified non-canonical tumor suppressing NOTCH3 activity. This proof-of-concept may be the basis for the design of innovative therapies aimed at specifically targeting oncogenic NOTCH signaling in CLL cells.

Supplementary Materials: The following are available online at http://www.mdpi.com/2073-4409/9/6/1484/s1, Figure S1: Detailed FACS data of CLL24 cells, Figure S2: Genomic distribution and characteristics of open chromatin sites in CLL cells in response to gliotoxin treatment, Figure S3: Overlap of differential ATAC-seq sites with public transcription factor binding datasets in gliotoxin treated CLL cells, Table S1: ATAC-seq gliotoxin response region cluster 1, Table S2: ATAC-seq gliotoxin response region cluster 2.

Author Contributions: Conceptualization, R.H. and M.S.; methodology, R.H., S.S., M.A., M.H. and F.A.; software, C.S. and A.F.R.; validation, R.H., M.S.; formal analysis, R.H.; investigation, R.H. and M.S.; resources, D.D., P.B.S., P.V., C.Z. and U.J.; data curation, M.H.; writing_original draft preparation, R.H.; writing-review and editing, R.H. and M.S.; visualization, R.H.; supervision, M.S.; project administration, R.H. and M.S.; funding acquisition, R.H. All authors have read and agreed to the published version of the manuscript.

Funding: This research was funded by the Austrian National Bank, “Jubilaeumsfonds"-Grant No. 13012; by the "Initiative Krebsforschung", UE71104017, UE1504001, and UE711043037; by a Clinical Research Grant of the Austrian Society of Hematology \& Oncology, AP00359OFF and by the WKO price 2017.

Acknowledgments: The authors kindly thank Christoph Bock for his technical support concerning ATAC-seq.

Conflicts of Interest: The authors declare no conflict of interest.

\section{References}

1. Chiorazzi, N.; Ferrarini, M. Cellular origin(s) of chronic lymphocytic leukemia: Cautionary notes and additional considerations and possibilities. Blood 2011, 117, 1781-1791. [CrossRef] [PubMed]

2. Burger, J.; Chiorazzi, N. B cell receptor signaling in chronic lymphocytic leukemia. Trends Immunol. 2013, 34, 592-601. [CrossRef] [PubMed]

3. Vardi, A.; Agathangelidis, A.; Sutton, L.-A.; Ghia, P.; Rosenquist, R.; Stamatopoulos, K. Immunogenetic Studies of Chronic Lymphocytic Leukemia: Revelations and Speculations about Ontogeny and Clinical Evolution. Cancer Res. 2014, 74, 4211-4216. [CrossRef]

4. Packham, G.; Krysov, S.; Allen, A.; Savelyeva, N.; Steele, A.J.; Forconi, F.; Stevenson, P.F.K. The outcome of B-cell receptor signaling in chronic lymphocytic leukemia: Proliferation or anergy. Haematologica 2014, 99, 1138-1148. [CrossRef] [PubMed]

5. Seifert, M.; Sellmann, L.; Bloehdorn, J.; Wein, F.; Stilgenbauer, S.; Dürig, J.; Küppers, R. Cellular origin and pathophysiology of chronic lymphocytic leukemia. J. Exp. Med. 2012, 209, 2183-2198. [CrossRef] [PubMed] 
6. Bosch, F.; Dalla-Favera, R. Chronic lymphocytic leukaemia: From genetics to treatment. Nat. Rev. Clin. Oncol. 2019, 16, 684-701. [CrossRef] [PubMed]

7. Hubmann, R.; Schwarzmeier, J.D.; Shehata, M.; Hilgarth, M.; Duechler, M.; Dettke, M.; Berger, R. Notch2 is involved in the overexpression of CD23 in B-cell chronic lymphocytic leukemia. Blood 2002, 99, 3742-3747. [CrossRef]

8. Rosati, E.; Sabatini, R.; Rampino, G.; Tabilio, A.; Di Ianni, M.; Fettucciari, K.; Bartoli, A.; Coaccioli, S.; Screpanti, I.; Marconi, P. Constitutively activated Notch signaling is involved in survival and apoptosis resistance of B-CLL cells. Blood 2009, 113, 856-865. [CrossRef]

9. Fabbri, G.; Holmes, A.B.; Viganotti, M.; Scuoppo, C.; Belver, L.; Herranz, D.; Yan, X.-J.; Kieso, Y.; Rossi, D.; Gaidano, G.; et al. Common nonmutational NOTCH1 activation in chronic lymphocytic leukemia. Proc. Natl. Acad. Sci. USA 2017, 114, E2911-E2919. [CrossRef]

10. De Falco, F.; Del Papa, B.; Baldoni, S.; Sabatini, R.; Falzetti, F.; Di Ianni, M.; Martelli, M.P.; Mezzasoma, F.; Pelullo, M.; Marconi, P.; et al. IL-4-dependent Jagged1 expression/processing is associated with survival of chronic lymphocytic leukemia cells but not with Notch activation. Cell Death Dis. 2018, 9, 1160. [CrossRef]

11. Secchiero, P.; Melloni, E.; Di Iasio, M.G.; Tiribelli, M.; Rimondi, E.; Corallini, F.; Gattei, V.; Zauli, G. Nutlin-3 up-regulates the expression of Notch1 in both myeloid and lymphoid leukemic cells, as part of a negative feedback antiapoptotic mechanism. Blood 2009, 113, 4300-4308. [CrossRef] [PubMed]

12. Puente, X.S.; Pinyol, M.; Quesada, V.; Conde, L.; Ordóñez, G.R.; Villamor, N.; Escaramis, G.; Jares, P.; Beà, S.; González-Díaz, M.; et al. Whole-genome sequencing identifies recurrent mutations in chronic lymphocytic leukaemia. Nature 2011, 475, 101-105. [CrossRef] [PubMed]

13. Fabbri, G.; Rasi, S.; Rossi, D.; Trifonov, V.; Khiabanian, H.; Ma, J.; Grunn, A.; Fangazio, M.; Capello, D.; Monti, S.; et al. Analysis of the chronic lymphocytic leukemia coding genome: Role of NOTCH1 mutational activation. J. Exp. Med. 2011, 208, 1389-1401. [CrossRef] [PubMed]

14. Rossi, D.; Rasi, S.; Fabbri, G.; Spina, V.; Fangazio, M.; Forconi, F.; Marasca, R.; Laurenti, L.; Bruscaggin, A.; Cerri, M.; et al. Mutations of NOTCH1 are an independent predictor of survival in chronic lymphocytic leukemia. Blood 2012, 119, 521-529. [CrossRef] [PubMed]

15. Weissmann, S.; Roller, A.; Jeromin, S.; Hernández, M.; Abáigar, M.; Hernández-Rivas, J.M.; Grossmann, V.; Haferlach, C.; Kern, W.; Haferlach, T.; et al. Prognostic impact and landscape of NOTCH1 mutations in chronic lymphocytic leukemia (CLL): A study on 852 patients. Leukemia 2013, 27, 2393-2396. [CrossRef] [PubMed]

16. López-Guerra, M.; Xargay-Torrent, S.; Rosich, L.; Montraveta, A.; Roldán, J.; Matas-Céspedes, A.; Villamor, N.; Aymerich, M.; Lopez-Otin, C.; Pérez-Galán, P.; et al. The $\gamma$-secretase inhibitor PF-03084014 combined with fludarabine antagonizes migration, invasion and angiogenesis in NOTCH1-mutated CLL cells. Leukemia 2014, 29, 96-106. [CrossRef]

17. Rosati, E.; Baldoni, S.; De Falco, F.; Del Papa, B.; Dorillo, E.; Rompietti, C.; Albi, E.; Falzetti, F.; Di Ianni, M.; Sportoletti, P. NOTCH1 Aberrations in Chronic Lymphocytic Leukemia. Front. Oncol. 2018, 8, 229. [CrossRef]

18. Hubmann, R.; Düchler, M.; Schnabl, S.; Hilgarth, M.; Demirtas, D.; Mitteregger, D.; Hölbl, A.; Vanura, K.; Le, T.; Look, T.; et al. NOTCH2 links protein kinase C delta to the expression of CD23 in chronic lymphocytic leukaemia (CLL) cells. Br. J. Haematol. 2010, 148, 868-878. [CrossRef]

19. Artavanis-Tsakonas, S. Notch Signaling: Cell Fate Control and Signal Integration in Development. Science 1999, 284, 770-776. [CrossRef]

20. Hori, K.; Sen, A.; Artavanis-Tsakonas, S. Notch signaling at a glance. J. Cell Sci. 2013, 126, $2135-2140$. [CrossRef]

21. Ntziachristos, P.; Lim, J.S.; Sage, J.; Aifantis, I. From fly wings to targeted cancer therapies: A centennial for notch signaling. Cancer Cell 2014, 25, 318-334. [CrossRef] [PubMed]

22. Henrique, D.; Schweisguth, F. Mechanisms of Notch signaling: A simple logic deployed in time and space. Development 2019, 146, dev172148. [CrossRef] [PubMed]

23. Ayaz, F.; Osborne, B.A. Non-canonical Notch Signaling in Cancer and Immunity. Front. Oncol. 2014, 4, 345. [CrossRef] [PubMed]

24. Cruickshank, M.N.; Ulgiati, D. The role of notch signaling in the development of a normal B-cell repertoire. Immunol. Cell Boil. 2009, 88, 117-124. [CrossRef] [PubMed]

25. Shukla, V.; Shukla, A.; Joshi, S.S.; Lu, R. Interferon regulatory factor 4 attenuates Notch signaling to suppress the development of chronic lymphocytic leukemia. Oncotarget 2016, 7, 41081-41094. [CrossRef] 
26. Lobry, C.; Oh, P.; Mansour, M.R.; Look, A.T.; Aifantis, I. Notch signaling: Switching an oncogene to a tumor suppressor. Blood 2014, 123, 2451-2459. [CrossRef] [PubMed]

27. Xiu, M.-X.; Liu, Y.-M. The role of oncogenic Notch2 signaling in cancer: A novel therapeutic target. Am. J. Cancer Res. 2019, 9, 837-854. [PubMed]

28. Espinoza, I.; Miele, L. Notch inhibitors for cancer treatment. Pharmacol. Ther. 2013, 139, 95-110. [CrossRef]

29. Andersson, E.R.; Lendahl, U. Therapeutic modulation of Notch signalling-Are we there yet? Nat. Rev. Drug Discov. 2014, 13, 357-378. [CrossRef]

30. Katoh, M.; Katoh, M. Precision medicine for human cancers with Notch signaling dysregulation (Review). Int. J. Mol. Med. 2020, 45, 279-297. [CrossRef]

31. Dobranowski, P.; Ban, F.; Cherkasov, A.; Black, P.C.; Contreras-Sanz, A. Perspectives on the discovery of NOTCH2-specific inhibitors. Chem. Boil. Drug Des. 2017, 91, 691-706. [CrossRef] [PubMed]

32. Hubmann, R.; Hilgarth, M.; Schnabl, S.; Ponath, E.; Reiter, M.; Demirtas, D.; Sieghart, W.; Valent, P.; Zielinski, C.; Jäger, U.; et al. Gliotoxin is a potent NOTCH2 transactivation inhibitor and efficiently induces apoptosis in chronic lymphocytic leukaemia (CLL) cells. Br. J. Haematol. 2012, 160, 618-629. [CrossRef] [PubMed]

33. Luistro, L.; He, W.; Smith, M.; Packman, K.; Vilenchik, M.; Carvajal, D.; Roberts, J.; Cai, J.; Berkofsky-Fessler, W.; Hilton, H.; et al. Preclinical profile of a potent gamma-secretase inhibitor targeting notch signaling with in vivo efficacy and pharmacodynamic properties. Cancer Res. 2009, 69, 7672-7680. [CrossRef] [PubMed]

34. Buenrostro, J.D.; Giresi, P.G.; Zaba, L.C.; Chang, H.Y.; Greenleaf, W.J. Transposition of native chromatin for fast and sensitive epigenomic profiling of open chromatin, DNA-binding proteins and nucleosome position. Nat. Methods 2013, 10, 1213-1218. [CrossRef] [PubMed]

35. Rendeiro, A.F.; Schmidl, C.; Strefford, J.C.; Walewska, R.; Davis, Z.; Farlik, M.; Oscier, D.; Bock, C. Chromatin accessibility maps of chronic lymphocytic leukaemia identify subtype-specific epigenome signatures and transcription regulatory networks. Nat. Commun. 2016, 7, 11938. [CrossRef]

36. Love, M.I.; Huber, W.; Anders, S. Moderated estimation of fold change and dispersion for RNA-seq data with DESeq2. Genome Boil. 2014, 15, 31. [CrossRef] [PubMed]

37. Heinz, S.; Benner, C.; Spann, N.; Bertolino, E.; Lin, Y.; Laslo, P.; Cheng, J.X.; Murre, C.; Singh, H.; Glass, C.K. Simple Combinations of Lineage-Determining Transcription Factors Prime cis-Regulatory Elements Required for Macrophage and B Cell Identities. Mol. Cell 2010, 38, 576-589. [CrossRef] [PubMed]

38. Sheffield, N.C.; Bock, C. LOLA: Enrichment analysis for genomic region sets and regulatory elements in R and Bioconductor. Bioinformtics 2015, 32, 587-589. [CrossRef] [PubMed]

39. Chen, E.Y.; Tan, C.M.; Kou, Y.; Duan, Q.; Wang, Z.; Meirelles, G.V.; Clark, N.R.; Ma'Ayan, A. Enrichr: Interactive and collaborative HTML5 gene list enrichment analysis tool. BMC Bioinform. 2013, 14, 128. [CrossRef]

40. Rosati, E.; Sabatini, R.; De Falco, F.; Del Papa, B.; Falzetti, F.; Di Ianni, M.; Cavalli, L.; Fettucciari, K.; Bartoli, A.; Screpanti, I.; et al. $\gamma$-Secretase inhibitor I induces apoptosis in chronic lymphocytic leukemia cells by proteasome inhibition, endoplasmic reticulum stress increase and notch down-regulation. Int. J. Cancer 2012, 132, 1940-1953. [CrossRef]

41. Herishanu, Y.; Pérez-Galán, P.; Liu, D.; Biancotto, A.; Pittaluga, S.; Vire, B.; Gibellini, F.; Njuguna, N.; Lee, E.; Stennett, L.; et al. The lymph node microenvironment promotes B-cell receptor signaling, NF- $\mathrm{kB}$ activation, and tumor proliferation in chronic lymphocytic leukemia. Blood 2011, 117, 563-574. [CrossRef] [PubMed]

42. Krysov, S.; Dias, S.; Paterson, A.; Mockridge, C.I.; Potter, K.N.; Smith, K.-A.; Ashton-Key, M.; Stevenson, P.F.K.; Packham, G. Surface IgM stimulation induces MEK1/2-dependent MYC expression in chronic lymphocytic leukemia cells. Blood 2012, 119, 170-179. [CrossRef] [PubMed]

43. Pozzo, F.; Bittolo, T.; Vendramini, E.; Bomben, R.; Bulian, P.; Rossi, F.M.; Zucchetto, A.; Tissino, E.; Degan, M.; D'Arena, G.; et al. NOTCH1-mutated chronic lymphocytic leukemia cells are characterized by a MYC-related overexpression of nucleophosmin 1 and ribosome-associated components. Leukemia 2017, 31, 2407-2415. [CrossRef] [PubMed]

44. Del Papa, B.; Baldoni, S.; Dorillo, E.; De Falco, F.; Rompietti, C.; Cecchini, D.; Cantelmi, M.G.; Sorcini, D.; Nogarotto, M.; Adamo, F.M.; et al. Decreased NOTCH1 Activation Correlates with Response to Ibrutinib in Chronic Lymphocytic Leukemia. Clin. Cancer Res. 2019, 25, 7540-7553. [CrossRef] [PubMed] 
45. López-Guerra, M.; Xargay-Torrent, S.; Fuentes, P.; Roldán, J.; González-Farré, B.; Rosich, L.; Silkenstedt, E.; García-León, M.J.; Lee-Vergés, E.; Giménez, N.; et al. Specific NOTCH1 antibody targets DLL4-induced proliferation, migration, and angiogenesis in NOTCH1-mutated CLL cells. Oncogene 2019, 39, 1185-1197. [CrossRef]

46. El-Asmar, B.; Giner, X.C.; Tremblay, J.J. Transcriptional cooperation between NF-кB p50 and CCAAT/enhancer binding protein $\beta$ regulates Nur77 transcription in Leydig cells. J. Mol. Endocrinol. 2008, 42, 131-138. [CrossRef]

47. Vacca, A.; Felli, M.P.; Palermo, R.; Di Mario, G.; Calce, A.; Di Giovine, M.; Frati, L.; Gulino, A.; Screpanti, I. Notch3 and pre-TCR interaction unveils distinct NF- $\kappa B$ pathways in T-cell development and leukemia. EMBO J. 2006, 25, 1000-1008. [CrossRef]

48. Del Bianco, C.; Vedenko, A.; Choi, S.H.; Berger, M.F.; Shokri, L.; Bulyk, M.L.; Blacklow, S.C. Notch and MAML-1 Complexation Do Not Detectably Alter the DNA Binding Specificity of the Transcription Factor CSL. PLoS ONE 2010, 5, e15034. [CrossRef]

49. Lauring, A.S.; Overbaugh, J. Evidence that an IRES within the Notch2 coding region can direct expression of a nuclear form of the protein. Mol. Cell 2000, 6, 939-945. [CrossRef]

50. Das, I.; Craig, C.; Funahashi, Y.; Jung, K.-M.; Kim, T.-W.; Byers, R.; Weng, A.P.; Kutok, J.L.; Aster, J.C.; Kitajewski, J.; et al. Notch Oncoproteins Depend on $\gamma$-Secretase/Presenilin Activity for Processing and Function. J. Boil. Chem. 2004, 279, 30771-30780. [CrossRef]

51. Hubmann, R.; Sieghart, W.; Schnabl, S.; Araghi, M.; Hilgarth, M.; Reiter, M.; Demirtas, D.; Valent, P.; Zielinski, C.; Jäger, U.; et al. Gliotoxin Targets Nuclear NOTCH2 in Human Solid Tumor Derived Cell Lines In Vitro and Inhibits Melanoma Growth in Xenograft Mouse Model. Front. Pharmacol. 2017, 8, 319. [CrossRef] [PubMed]

52. Lee, J.M.; Lee, K.-H.; Weidner-Glunde, M.; Osborne, B.A.; Hayward, S.D. Epstein-Barr virus EBNA2 blocks Nur77-mediated apoptosis. Proc. Natl. Acad. Sci. USA 2002, 99, 11878-11883. [CrossRef] [PubMed]

53. Deutsch, A.; Rinner, B.; Wenzl, K.; Pichler, M.; Troppan, K.; Steinbauer, E.; Schwarzenbacher, D.; Reitter, S.; Feichtinger, J.; Tierling, S.; et al. NR4A1-mediated apoptosis suppresses lymphomagenesis and is associated with a favorable cancer-specific survival in patients with aggressive B-cell lymphomas. Blood 2014, 123, 2367-2377. [CrossRef] [PubMed]

54. Tan, C.; Noviski, M.; Huizar, J.; Zikherman, J. Self-reactivity on a spectrum: A sliding scale of peripheral B cell tolerance. Immunol. Rev. 2019, 292, 37-60. [CrossRef]

55. Miele, L. Transcription factor RBPJ/CSL: A genome-wide look at transcriptional regulation. Proc. Natl. Acad. Sci. USA 2011, 108, 14715-14716. [CrossRef]

56. Shimizu, K.; Chiba, S.; Saito, T.; Kumano, K.; Hamada, Y.; Hirai, H. Functional Diversity among Notch1, Notch2, and Notch3 Receptors. Biochem. Biophys. Res. Commun. 2002, 291, 775-779. [CrossRef]

57. Beatus, P.; Lundkvist, J.; Oberg, C.; Lendahl, U. The notch 3 intracellular domain represses notch 1-mediated activation through Hairy/Enhancer of split (HES) promoters. Development 1999, 126, 3925-3935.

58. Baeten, J.T.; Lilly, B. Differential Regulation of NOTCH2 and NOTCH3 Contribute to Their Unique Functions in Vascular Smooth Muscle Cells. J. Boil. Chem. 2015, 290, 16226-16237. [CrossRef] [PubMed]

59. Yuan, Y.; Wang, X.; Sun, Q.; Dai, X.; Cai, Y. MicroRNA-16 is involved in the pathogenesis of pre-eclampsia via regulation of Notch2. J. Cell. Physiol. 2019, 235, 4530-4544. [CrossRef]

60. Tumang, J.R.; Hastings, W.D.; Bai, C.; Rothstein, T.L. Peritoneal and splenic B-1 cells are separable by phenotypic, functional, and transcriptomic characteristics. Eur. J. Immunol. 2004, 34, 2158-2167. [CrossRef]

61. Stache, V.; Verlaat, L.; Gätjen, M.; Heinig, K.; Westermann, J.; Rehm, A.; Höpken, U.E. The splenic marginal zone shapes the phenotype of leukemia B cells and facilitates their niche-specific retention and survival. OncoImmunology 2017, 6, e1323155. [CrossRef] [PubMed]

62. Descatoire, M.; Weller, S.; Irtan, S.; Sarnacki, S.; Feuillard, J.; Storck, S.; Guiochon-Mantel, A.; Bouligand, J.; Morali, A.; Cohen, J.; et al. Identification of a human splenic marginal zone B cell precursor with NOTCH2-dependent differentiation properties. J. Exp. Med. 2014, 211, 987-1000. [CrossRef] [PubMed]

63. Kuang, S.-Q.; Fang, Z.; Zweidler-McKay, P.A.; Yang, H.; Wei, Y.; Gonzalez-Cervantes, E.A.; Boumber, Y.; Quintás, G. Epigenetic Inactivation of Notch-Hes Pathway in Human B-Cell Acute Lymphoblastic Leukemia. PLoS ONE 2013, 8, e61807. [CrossRef] [PubMed]

64. Oliveto, S.; Mancino, M.; Manfrini, N.; Biffo, S. Role of microRNAs in translation regulation and cancer. World J. Boil. Chem. 2017, 8, 45-56. [CrossRef] [PubMed] 
65. Wu-Zhang, A.X.; Newton, A.C. Protein kinase C pharmacology: Refining the toolbox. Biochem. J. 2013, 452, 195-209. [CrossRef] [PubMed]

66. Mecklenbräuker, I.; Saijo, K.; Zheng, N.-Y.; Leitges, M.; Tarakhovsky, A. Protein kinase C $\delta$ controls self-antigen-induced B-cell tolerance. Nature 2002, 416, 860-865. [CrossRef]

67. Ringshausen, I.; Schneller, F.; Bogner, C.; Hipp, S.; Duyster, J.; Peschel, C.; Decker, T. Constitutively activated phosphatidylinositol-3 kinase (PI-3K) is involved in the defect of apoptosis in B-CLL: Association with protein kinase C $\delta$. Blood 2002, 100, 3741-3748. [CrossRef]

68. Zhu, F.; Sweetwyne, M.T.; Hankenson, K. PKC $\delta$ Is Required for Jagged-1 Induction of Human Mesenchymal Stem Cell Osteogenic Differentiation. Stem Cells 2013, 31, 1181-1192. [CrossRef]

69. Balakrishnan, K.; Peluso, M.; Fu, M.; Rosin, N.Y.; A Burger, J.; Wierda, W.G.; Keating, M.J.; Faia, K.; O’Brien, S.; Kutok, J.L.; et al. The phosphoinositide-3-kinase (PI3K)-delta and gamma inhibitor, IPI-145 (Duvelisib), overcomes signals from the PI3K/AKT/S6 pathway and promotes apoptosis in CLL. Leukemia 2015, 29, 1811-1822. [CrossRef]

(C) 2020 by the authors. Licensee MDPI, Basel, Switzerland. This article is an open access article distributed under the terms and conditions of the Creative Commons Attribution (CC BY) license (http://creativecommons.org/licenses/by/4.0/). 